\title{
Uncertainty and Sensitivity in Surface Dynamics Modeling
}

Albert J. Kettner and James P.M. Syvitski. Community Surface Dynamics Modeling System (CSDMS) Integration Facility, INSTAAR, University of Colorado, Boulder, CO, USA, kettner@colorado.edu; http://csdms.colorado.edu

\subsection{Introduction}

Papers for this special issue on 'Uncertainty and Sensitivity in Surface Dynamics Modeling' heralds from papers submitted after the 2014 annual meeting of the Community Surface Dynamics Modeling System or CSDMS. CSDMS facilitates a diverse community of experts (now in 68 countries) that collectively investigate the Earth's surface - the dynamic interface between lithosphere, hydrosphere, cryosphere, and atmosphere, by promoting, developing, supporting and disseminating integrated open source software modules. By organizing more than 1500 researchers, CSDMS has the privilege of identifying community strengths and weaknesses in the practice of software development. We recognize, for example, that progress has been slow on identifying and quantifying uncertainty and sensitivity in numerical modeling of earth's surface dynamics. This special issue is meant to raise awareness for these important subjects and highlight state-of-the-art progress.

Numerical models of earth's surface dynamics typically consist of algorithms that describe complex real-world phenomena. Inevitably these algorithms are a simplification. Geoscience has not evolved to the point were we can or even want to fully describe all natural processes from first-principles. For practical reasons we often include just key processes that capture the essence of natural phenomena. Simplification might be for reasons of model skill, computing skill, or limits of knowledge. Model uncertainty is introduced when complex natural processes are simplified (Heuvelink, 1998), and uncertainly can be both amplified or dampened when multiple algorithms are joined in a coupled or complex model (Fig. 1). Uncertainty can also be introduced at the model input parameter level, as it is only 
in rare cases that all input parameters are known with certainty (Oreskes et al., 1994; Kurowicka and Cooke, 2006). More often, accurate model input data is either not available or too expensive to obtain (Fig. 1). Sensitivity analyses can help determining the importance of model input parameters. Sensitivity analyses can also help determine if a model is suitable for a particular study site, thus identifying if another model might be a better alternative to provide model estimates.

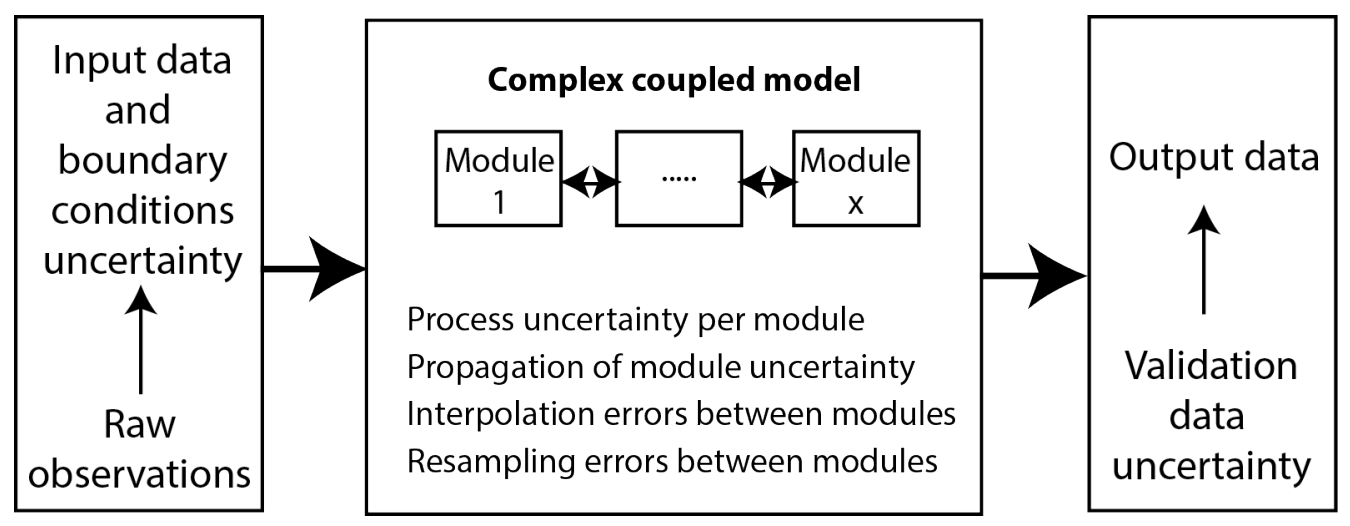

Figure 1. Uncertainties and how they propagate through a modeling simulation workflow.

This special issue provides examples of how uncertainty can be quantified and parameter sensitivity derived. Below we provide a brief overview of the special issue, and identify some of the challenges our community still faces when it comes to sensitivity and uncertainty analyzes in numerical modeling.

\subsection{Special issue overview}

Each of the 14 special issue papers discuss progress made in - or applications of uncertainty and /or sensitivity analyses in a broad field of earth-surface dynamics modeling. Five papers focus on model sensitivity, five papers discuss uncertainties in modeling, and four papers discuss both model sensitivity analysis and uncertainties. 
Earth science numerical models are developed and applied to explain and predict the behavior of the earth. This fulfills a central role within the geosciences. However, as Halpern (1998) indicates: 'Uncertainty is a fundamental - well unavoidable feature of daily life'. Mathematical methods can identify the degree of uncertainty and sensitivity analyses can identify how uncertainty in model output can be attributed to different sources of uncertainty in the model input (Saltelli et al., 2008). Being able to quantify uncertainty in model outcome adds towards the degree of confidence we have in simulation results. There is no such thing as quantifying the uncertainty of an earth science model without having a particular decision question or practical application in mind (Caers, 2011). Along these lines, Murray et al. (this issue) propose that quantifying uncertainty may only be justifiable for simulating models as these models are almost always process-based and have societal relevance. Some earth surface models are only partly processbased. Uncertainty studies would therefore only reveal model precision, not how well simulations match observations.

\subsection{Sensitivity and Uncertainty studies applied to the Coastal zone}

Nearly half (44\%) of the world population lives within $150 \mathrm{~km}$ of the ocean (UN atlas). Higher growth rates are found in the coastal zone often due to migration away from the hinterland and there is no sign that this will change in the $21^{\text {st }}$ century (Neumann et al., 2015). With current sea-level rise rates, low-land coastal zones are more vulnerable to flooding. Storm surges set up by tropical cyclones will increase due to sea-level rise (Woodruff et al., 2013). This increasing flood risk promotes an interest in developing operational early warning-systems for extreme coastal conditions. Baart et al. (this issue) discuss morphological storm impact forecasts, i.e. spatially distributed erosion and deposition along the coastal zone, and argues that these are only relevant when accurate, timely and with known confidence. Confidence decreases with an increasing model forecasting horizon, even though longer forecasting times are desired to implement proper measures like e.g. evacuating people. A set of statistical measures: anomaly correlation, mean 
squared error, root mean squared error and forecast skill score, are applied to analyze and discuss how well state-of-the-art coupled coastal modules perform in forecasting morphological changes due to storms.

Large events like cyclones or hurricanes affect morphological changes of the subaerial coastal zone and typically induce significant sediment transport of reworked material on shelves resulting in erosional and depositional areas. Modeling the morphological impact of these large events is a common strategy because observational records are sparse as instruments can easily be hampered or displaced by these events. Xu et al. (this issue) applies the Regional Ocean Modeling System (ROMS) to investigate morphological changes for the Louisiana shelf as a result of Hurricanes Katrina and Rita. Model uncertainty and sensitivity are utilized to investigate how well ROMS is capable of capturing realistic morphological changes on the shelf. The study indicates that the magnitude of morphological change is especially sensitive to model input parameters, where spatial changes in the morphology is mostly affected by the location of the hurricane tracks, bed shear stresses, grain size and shelf bathymetry.

Given certain wave conditions, fine sediments, mainly resuspended from the shelf, can be transported by the wave bottom boundary layer offshore to continental margins. Better understanding of this mechanism improves insight in offshore carbon storage mechanisms, as organic matter concentrations correlate positively with fine sediment concentrations. Upward flow motion induced by particle interaction causes a hindered settling effect, making it possible to keep fine sediments in resuspension for a long time. Parameterization of the hindered effect in numerical models is not well constrained due to variability in floc structures. Particle inertia is often ignored in turbulence-resolving studies. Cheng et al. (this issue) evaluates uncertainty of fine sediment transport in the wave boundary layer associated with this parameterization applying a highly accurate turbulenceresolving model. Results reveal that particle inertia is negligible under certain conditions of fine sediment transport. However Cheng et al. (this issue) nicely show that flocculated particles impact the hindered settling effect, keeping particles in 
resuspension and therefore impacting seafloor sediment mobility. Floc properties must be taken into account to reduce uncertainty when studying sediment transport in wave bottom boundary layers, and ultimately any associated carbon removal.

Cheng et al. (this issue) provide a good example of how important wave events can be. Being able to simulate wave dynamics accurately will reduce uncertainties in for example the resuspension of sediments. Siadatmousavi et al. (this issue) analyzed model sensitivity of the third generation wave model SWAN to changing boundary conditions as simulated by different modules that capture the white capping dissipation process. Results indicate that the quality of input parameters (high temporal and spatial resolution wind data) correlates positively with the accuracy of simulated waves. The nonlinear saturation-based white capping module gave the best model performance compared to inshore buoy observations. Further offshore, the WAM white capping dissipation modules seem to perform better when comparing to remote sensed wave data.

\subsection{Sensitivity and Uncertainty studies applied to Hydrological processes}

The Earth's water surface is more than twice as large as the land surface, but only $2.5 \%$ of that water is actual freshwater, of which almost $69 \%$ is not direct accessible as it is stored as icecaps, glaciers and permanent snowfields (Shiklomanov, 1993). The rate at which the global hydrologic cycle replenishes freshwater resources that determines the freshwater availability for human use (Engelman and LeRoy, 1993). Pressure on quantity and quality of freshwater is most likely to rise as demands increase with a growing global population to fulfill agricultural, industrial, and domestic needs. Already 4 billion people experience or live in areas of severe water scarcity for at least 1 month of the year, of which half a billion face severe water scarcity all year round (Mekonnen and Hoekstra, 2016). A better spatial and temporal understanding of hydrological processes is needed to serve society, however there are limitations of hydrological measurement techniques as well as available temporal and spatial coverage (Beven, 2001). Being able to accurately simulate surface and groundwater flows helps us better assess freshwater 
resources. Mockler et al. (this issue) presents a parameter sensitivity analysis applying three conceptual hydrological flow models to 31 catchments in Ireland. Their findings reveal that freshwater quality is most accurately assessed when all aspects of flow (i.e. overland flow, interflow, upper and lower groundwater flow) are considered in any model configuration.

Models become more complex when studying multiple flow fluxes in both the unsaturated and saturated zones of the subsurface, and require subsurface characterization input parameters that can never be fully resolved. Model input uncertainty is introduced when establishing input layers for these integrated hydrological models. To determine the impact of such parameterizations, traditional sensitivity analysis requires a large number of simulations given the many input parameters. Jefferson et al. (this issue) successfully apply a novel method, 'the active subspace method' to analyze parameter sensitivity of integrated hydrological models. The method identifies dominant input parameters contributing to uncertainty and how combined inputs relate to model output. The method requires less compute time compared to more traditional sensitivity analyzes methods, such as a Monte Carlo approach.

An important part of the hydrologic cycle consists of evapotranspiration. Therefore accurate quantification of evapotranspiration provides a greater understanding of the water cycle in a region (Long et al., 2014). Here, Yu et al. (this issue) present a method to quantify uncertainty of evapotranspiration for hydrological models for forest ecosystems. Long-term evapotranspiration measurements are sparse so simulated hydrological parameters are compared with observations - assuming that uncertainty in evapotranspiration will affect the water balance. Findings demonstrate that coupling vegetation models (e.g. Biome-BGC) with hydrological catchment models (e.g. PIHM) reduces the uncertainty in overall hydrologic variability.

\subsection{Sensitivity and Uncertainty studies applied to the terrestrial processes}


In the early 1970s, Ahnert (1976) among others developed a three-dimensional model to simulated hill slope forms. A linkage between tectonics and topography was therefore adapted and explored in the 1990s when the first Landscape Evolution numerical Models (LEMs) were developed (Bischop, 2007; Tucker and Hancock, 2010). It is now well accepted that the interaction of fluvial and tectonic processes are key processes forming the earth surface (e.g. Wobus et al., 2006; Tucker, 2009; Tucker and Hancock, 2010). To investigate the impact of each of the two processes to the earth surface evolution separately, Roy et al. (this issue) developed a cutting edge method, quantifying orientation and scale dependence of topographic anisotropy. Findings show that at the orogenic scale, tectonic processes are the dominant factor in controlling topography where fluvial networks typically emphases the underlying tectonic structures by increasing erosion rates at for example faults.

Once catchment scale topography emerges, it has significant impact on hydrological and geomorphological processes (Moore et al., 1991). Unlike legacy digital representations of topography, most DEMs are produced from detailed remotely sensed measurements. These measurements are usually subject to error (Gallant, 2011) and may contain random perturbations (Fig. 1; raw data). Uncertainties in sediment transport and landscape evolution, caused by these DEM perturbations are investigated by Hancock et al. (this issue). Changes in DEM perturbation patterns and magnitudes result in statistically similar morphological landscapes but differences express themselves in the patterns of erosion and deposition.

Landscape Evolution Models typically under-recognize the role of soils (Minasny et al., 2015). As landscape erodes, LEMs simply redistribute weathered material, not considering soil properties that could interact with the erosion and transport processes. Temme and Vanwalleghem (this issue) make a compelling case that soils and landscapes are closely intertwined and therefore soil processes should be included in LEMs. By performing parameter sensitivity analyzes for a new soillandscape model LORICA, Temme and Vanwalleghem (this issue) show that soil formation parameters, such as variables controlling the amount and position of fine 
clay, have more impact on the geomorphic evolution of landscapes than geomorphological parameters, like erosion and deposition.

LEMs are rarely applied as 'operational models' or used in the engineering world. This might change in the nearby future, at least for advanced geomorphological models that mimic short-timescale processes like riverbed evolution or debris flow models. Morphodynamic models are more commonly applied, but these models still use simi-empirical sediment transport, and therefore offer less accurate results. To reduce inaccuracy, calibration of the most sensitive model input parameters is inevitable (Villaret et al., this issue). By applying a first-order second moment method using Algorithmic Differentiation, Villaret et al. (this issue) show that parameters that describe settling velocity and grain size are the most sensitive input parameters for the Telemac-2D/Sisyphe Morphodynamic model when studying the evolution of a riverbed.

\subsection{Numerical or computational advances in Sensitivity and Uncertainty}

Modeling Frameworks for Earth surface processes have emerged since the early 2000s. They tend to offer modularity, such that a user can couple a set of selected modules in a 'plug and play' environment, to build and run a model composite. Modeling Frameworks get more attention because of their capability to: promote reuse of already existing modules; couple models simulating different environmental domains, or numerical styles (languages, grids, time-stepping); and, compare similar domain modules. Service components like e.g. time stepping, regridding and/or writing output to a standardized format can be made available to individual modules or to model composites (Syvitski et al., 2014). Peckham et al. (this issue) discusses a new set of possible framework functionalities that are becoming integrated in the CSDMS framework: the 'model uncertainty components'. This toolkit of uncertainty components can be called within the framework to derive uncertainty quantifications and parameter estimations for stand alone and coupled modules. Furthermore, Peckham et al. (this issue) serves as a guide to software toolkits for uncertainty quantification, inverse modeling and data assimilation. 
The capability of coupling modules might also introduce error or uncertainty as for example module surface boundaries need to be regridded to being able to exchange information, or adjustments need to be made to spatial and or temperate scales of individual modules (Fig. 1). Belete and Voinov (this issue) discuss specifically the sensitivity of model characteristics that are related to model composites by analyzing variations in: a) time stepping, b) the effect of using different numerical methods and, c) changes in functional responses between modules that describe the same processes. This is illustrated by componentizing a simple predator-prey model into two modules that are coupled through a web interface. Preliminary outcomes indicate the importance of performing sensitivity analyzes of time stepping and functional synchronization when integrating modules.

\subsection{Accessibility of model uncertainty and parameter sensitivity toolkits in the Geosciences}

Sciences that apply computational methods are having, to various degrees, difficulty handling the concept of numerical predictability, uncertainty quantification and model validation. As models become more complex, so does the need to assess their validity especially when full-scale testing is not possible (Oreskes et al., 1994; Hemez and Doebling, 2001). Today's complex models can access model coupling frameworks, powerful computing clusters and high spatial and temporal resolution input parameters. There is a growing societal demand for more complex models. For example models that incorporate meteorologic, climatic and tectonic processes to predict future changes in the earth-surface system, so called 'Earthcasts' (Murray et al., 2009). Complex models require multi-dimensional input parameters, leading to an increase in model input parameters some of which need to be estimated and thus pose an ill-conditioned problem (Pokhrel et al., 2008).

Scientists are also increasingly relying on numerical model outcomes to replace physical measurements. A better understanding and trustworthiness of numerical schemes are needed for model-based decision support, such as policy analysis, 
integrated assessment, risk assessment, and environmental impact assessment. Each requires some integration of uncertainty quantification (Walker et al., 2003), thus providing for better policies. Recognizing the need to better understand uncertainties in model results, the U.S. Department of Energy's (DOE's) National Nuclear Security Administration, the DOE's Office of Science, and the U.S. Air Force Office of Scientific Research requested that the U.S. National Research Council study the mathematical sciences foundations of verification, validation, and uncertainty quantification (NRC, 2012). Key uncertainty research topics (NRC 2012) that fit the scope of this special issue include:

- Development of methods for propagating and aggregating uncertainties and sensitivities across hierarchies of models.

- Development of algorithms and strategies across the spectrum of uncertainty qualification related tasks that can efficiently use modern and future massively parallel computer architectures.

There is a growing recognition that model frameworks and model web services can support scientists in providing easy access to state of the art toolkits to quantify uncertainty and track uncertainty propagation through a model chain (Schulz, et al., 2012). Examples include European efforts to the develop an Uncertainty Markup Language (UncertML) for GIS platforms by Williams et al. (2009), or recent efforts in the United States, by the CSDMS Integration Facility, to integrate modules of DAKOTA into model frameworks. DAKOTA is a multilevel parallel object-oriented framework useful for design optimization, parameter estimation, uncertainty quantification, and sensitivity analysis (Adams et al., 2013), and is available through the CSDMS Web Modeling Tool (WMT) (Syvitski et al., 2014).

Uncertainty quantification should become standard parts of the respective core curricula for environmental scientists, engineers, and statisticians. Future numerical modeling advances will be determined in part by how well uncertainty quantification is integrated into computational models and methods and as supported by computing infrastructure (NRC, 2012). 


\section{Acknowledgements}

We thank all attendees of the 2014 CSDMS annual meeting. Their enthusiasm and inspiration resulted in pursuing this special issue. A special thanks goes to the contributors of this special issue. We acknowledge the National Science Foundation as the major sponsor of the CSDMS effort (0621695). We also kindly acknowledge all reviewers for their time and effort. We particularly thank Jef Caers, the C\&G Editor-in-Chief for creating this opportunity and for his close involvement with the review process.

\section{References}

\section{(Red colored refs are part of this SI)}

Adams, B.M., Bauman, L.E., Bohnhoff, W.J., Dalbey, K.R., Ebeida, M.S., Eddy, J.P., Eldred, M.S., Hough, P.D., Hu, K.T., Jakeman, J.D., Swiler, L.P., and Vigil, D.M., "DAKOTA, A Multilevel Parallel Object-Oriented Framework for Design Optimization, Parameter Estimation, Uncertainty Quantification, and Sensitivity Analysis: Version 5.4 User's Manual," Sandia Technical Report SAND2010-2183, December 2009. Updated April 2013. URL: https://dakota.sandia.gov/sites/default/files/docs/5.4/Users-5.4.0.pdf

Ahnert, F., 1976. Brief description of a comprehensive three-dimensional model of landform development. Zeitschrift fur Geomorphologie Supplement Band 25: 2949.

Baart, F., van Ormondt, M., van Thiel de Vries, J., and van Koningsveld, M., 2016. Morphological impact of a storm can be predicted three days ahead. Computers \& Geosciences, xxx. doi:10.1016/j.cageo.2015.11.011.

Belete, G.F., and Voinov, A., 2016. Exploring temporal and functional synchronization in integrating models: A sensitivity analysis. Computers \& Geosciences. doi:10.1016/j.cageo.2015.09.006.

Beven, K.J., 2001. Rainfall-Runoff modelling - the primer. Wiley, Chichester, 360 pp.

Bishop, P., 2007. Long-term landscape evolution: linking tectonics and surface processes. Earth Surface Processes and Landforms, 32, 329-365. Doi: 10.1002/esp.1493.

Caers, J., 2011. Modeling Uncertainty: Concepts and Philosophies, in Modeling Uncertainty in the Earth Sciences, John Wiley \& Sons, Ltd, Chichester, UK. doi: 10.1002/9781119995920.ch3

Cheng, Z., Yu, X., Hsu, T.-J., and Balachandar, S., 2015. A numerical investigation of fine sediment resuspension in the wave boundary layer-Uncertainties in particle inertia and hindered settling, Computers \& Geosciences, 83, 176-192. doi:10.1016/j.cageo.2015.07.009. 
Engelman, R., and LeRoy, P., 1993. Sustaining water: Population and the future of renewable water supplies. Population and environment program, population action international, Washington DC, p. 56 [Document Number PIP/092932].

Gallant, J., 2011. Adaptive Smoothing for Noisy DEMs. Geomorphometry 2011. California, USA.

Halpern, J. Y., 1998. A logical approach to reasoning about uncertainty: a tutorial (pp. 141-155). Springer Netherlands.

Hancock, G.R., Coulthard, T.J., and Lowry, J.B.C., 2016. Predicting uncertainty in sediment transport and landscape evolution - the influence of initial surface conditions, Computers \& Geosciences. doi:10.1016/j.cageo.2015.08.014.

Hemez, F. M. and Doebling, S. W., 'Uncertainty, validation of computer models and the myth of numerical predictability', in Proceedings of the International Conference on Structural System Identification, Kassel, Germany, 2001, pp. 13-35.

Heuvelink, G.B.M., Error Propagation in Environmental Modelling with GIS Research Monographs in GIS. CRC Press, 144 pp., London, 1998.

Jefferson, J.L., Gilbert, J.M., Constantine, P.G., and Maxwell, R.M., 2015. Active subspaces for sensitivity analysis and dimension reduction of an integrated hydrologic model. Computers \& Geosciences, 83, 127-138. doi: 10.1016/j.cageo.2015.07.001.

Kurowicka, D., and Cooke, R.M., 2006. Uncertainty analysis with high dimensional dependence modelling, John Wiley \& Sons.

Long, D., Longuevergne, L., and Scanlon, B.R., 2014. Uncertainty in evapotranspiration from land surface modeling, remote sensing, and GRACE satellites. Water Resources Research, 50, 1131-1151. Doi: 10.1002/2013WR014581

Mekonnen, M.M., and Hoekstra, A.Y., 2016. Four billion people facing severe water scarcity. Science Advances, 2, e1500323. Doi: 10.1126/sciadv.1500323

Minasny, B., Finke, P., Stockmann, U., Vanwalleghem, T., and McBratney, A.B., 2015. Resolving the integral connection between pedogenesis and landscape evolution. Earth-Science Reviews, 150, 102-120. Doi: 10.1016/j.earscirev.2015.07.004

Mockler, E.M., O'Loughlin, F.E., and Bruen, M., 2016. Understanding hydrological flow paths in conceptual catchment models using uncertainty and sensitivity analysis, Computers \& Geosciences, xxx. doi:10.1016/j.cageo.2015.08.015.

Moore, I. D., Grayson, R. B. and Ladson, A. R. (1991), Digital terrain modelling: A review of hydrological, geomorphological, and biological applications. Hydrol. Process., 5: 3-30. doi: 10.1002/hyp.3360050103

Murray, A.B., Gasparaini, N.M., Goldstein, E.B., and van der Wegen, M., 2016. Uncertainty quantification in modeling Earth surface processes: It's most applicable at one end of the spectrum of model types. Computers \& Geosciences, $\mathrm{xxx}$. (in review) 
Murray, A.B., Lazarus, E., Ashton, A., Baas, A., Coco, G., Coulthard, T., Fonstad, M., Haff, P., McNamara, D., Paola, C., Pelletier, J., and Reinhardt, L., 2009. Geomorphology, complexity, and the emerging science of the Earth's surface. Geomorphology, 103, 496-505. Doi: 10.1016/j.geomorph.2008.08.013.

Neuman, B., Vafeidis, A.T., Zimmermann, J., and Nicholls, R.J., 2015. Future Coastal Population Growth and Exposure to Sea-Level Rise and Coastal Flooding - A Global Assessment. PLoS ONE 10(3): e0118571. doi: 10.1371/journal.pone.0118571

National Research Council. 2012. Assessing the Reliability of Complex Models: Mathematical and Statistical Foundations of Verification, Validation, and Uncertainty Quantification. Washington, D.C.: The National Academies Press.

Oreskes, N., Shrader-Frechette, K., and Belitz, K., 1994. Verification, Validation, and Confirmation of Numerical Models in the Earth Sciences. Science, 263, 641- 646. Stable URL: http://www.jstor.org/stable/2883078.

Peckham, S.D., et al., 2016. Model Uncertainty and Parameter Estimation Components in an Earth System Modeling Framework Environment. Computers $\&$ Geosciences, xxx. (in review)

Pokhrel, P., Gupta, H.V., and Wagener, T., 2008. A spatial regularization approach to parameter estimation for a distributed watershed model. Water resources research, 44, W12419. Doi: 10.1029/2007WR006615

Roy, S.G., Koons, P.O., Osti, B., Upton, P., and Tucker, G.E., 2016. Multi-scale characterization of topographic anisotropy. Computers \& Geosciences, xxx. Doi: 10.1016/j.cageo.2015.09.023

Saltelli, A., Ratto, M., Andres, T., Campolongo, F., Cariboni, J., Gatelli, D., Saisana, M., and Tarantola, S. 2008. Global Sensitivity Analysis. The Primer, John Wiley and Sons.

Schulz, M., Skøien, J.O., Gerharz, L., Dubois, G., and Pebesma, E., 2012. Uncertainty propagation between web services - a case study using the eHabitat WPS to identify unique ecosystems. In: "6th International Congress on Environmental Modelling and Software - iEMSs 2012", July 1-5, 2012, Leipzig, Germany. URL: http://www.uncertweb.org/uploads/papers/a1d504ee65db72a1d270ac938f66 a34d3fee18b3.pdf

Shiklomanov, I. 1993. World fresh water resources in Peter H. Gleick (editor), 1993, Water in Crisis: A Guide to the World's Fresh Water Resources, Oxford University Press, New York.

Siadatmousavi, S.M., Jose, F., and Silva, G.M., 2016. Sensitivity of a third generation wave model to wind and boundary condition sources and model physics: a case study from the South Atlantic Ocean off Brazil Coast Computers \& Geosciences, xxx. doi: 10.1016/j.cageo.2015.09.025.

Syvitski, J.P.M., Hutton, E.W.H., Piper, M.D., Overeem, I., Kettner, A.J., and Peckham, S.D., 2014. Plug and Play Component Modeling - The CSDMS2.0 Approach. In 
Proceedings of the 7th Intl. Congress on Env. Modelling and Software, International Environmental Modelling and Software Society (iEMSs). San Diego, CA, 2014.

Temme, A.J.A.M., and Vanwalleghem, T., 2016. LORICA - A new model for linking landscape and soil profile evolution: Development and sensitivity analysis, Computers \& Geosciences, xxx. doi:10.1016/j.cageo.2015.08.004.

Thornbury W.D., 1969. Principles of Geomorphology, 2nd edn. Wiley: New York.

Tucker, G.E., 2009, Natural experiments in landscape evolution: Earth Surface Processes and Landforms, 34, 1450- 1460. doi:10.1002/esp.1833.

Tucker, G.E., and Hancock, G.R., 2010. Modelling landscape evolution. Earth Surface Processes and Landforms, 35, 28-50. Doi: 10.1002/esp.1952.

UN atlas; see: http://coastalchallenges.com/2010/01/31/un-atlas-60-of-us-live-inthe-coastal-areas/

Villaret, C.L., Kopmann, R., Riehme, J., Wyncoll, D., Merkel, U., and Naumann, U., 2016. First-order Uncertainty Analysis using Algorithmic Differentiation of the Telemac-2D/Sisyphe Morphodynamic Model. Computers \& Geosciences, xxx. Doi: 10.1016/j.cageo.2015.10.012.

Walker, W.E., Harremoës, P., Rotmans, J., van der Sluijs, J.P., van Asselt, M.B.A., Janssen, P., and Krayer Von Krauss, M.P., 2003. Defining uncertainty: a conceptual basis for uncertainty management in model-based decision support. Integrated Assessment, 4, 5-17. Doi: 10.1076/iaij.4.1.5.16466.

Williams, M., Cornford, D., Bastin, L., and Pebesma, E., 2009. Uncertainty markup language (UncertML). OpenGIS Discussion Paper 08-122r2, Open Geospatial Consortium Inc. URL: http://portal.opengeospatial.org/files/?artifact_id=33234.

Wobus, C.W., Whipple, K.X., Kirby, E., Snyder, N., Johnson, J., Spyropolou, K., Crosby, B., and Sheehan, D., 2006. Tectonics from topography: procedures, promise, pitfalls, in Willett, S., et al., eds., Tectonics, Climate, and Landscape Evolution: Geological Society of America Special Paper 398, p. 55-74.

Woodruff, J.D., Irish, J.L., and Camargo, S.J., 2013. Coastal flooding by tropical cyclones and sea-level rise. Nature, v.504, 44-52. Doi: 10.1038/nature12855.

Xu, K., Mickey, R.C., Chen, Q.J., Harris, C.K., Hetland, R.D., Hu, K., and Wang, J., 2016. Shelf Sediment Transport during Hurricanes Katrina and Rita. Computers \& Geosciences, xxx. doi:10.1016/j.cageo.2015.10.009.

Yu, X., Lamačová, A., Duffy, C., Krám, P., and Hruška, J., 2016. Hydrological model uncertainty due to spatial evapotranspiration estimation methods. Computers \& Geosciences, xxx. doi:10.1016/j.cageo.2015.05.006. 